\title{
Reviews
}

\section{The endogenous regulation of mosquito reproductive behavior}

\author{
M. J. Klowden \\ Division of Entomology, University of Idaho, Moscow (Idaho 83843, USA) \\ Communicated by E. Kubli, Editorial Board
}

Summary. Most female mosquitoes require a meal of blood that provides protein for egg maturation. For reproduction to occur, two behavioral sequences are essential. One is concerned with finding a host for the blood meal and the other in finding a site on which to lay the eggs that result. Stimuli from both hosts and oviposition sites initiate the reproductive behaviors of host-seeking and pre-oviposition, respectively, that are discussed in this review. After sensory receptors perceive these stimuli, the central nervous system must integrate the information and associate it with a biologically appropriate response. Host-seeking appears to be the default behavior, expressed whenever host stimuli are present. However, if the female is successful in locating a host and ingesting blood, subsequent host-seeking is inhibited when the meal distends the abdomen above a certain threshold. Host-seeking inhibition continues during egg development as a result of a humoral mechanism even after the blood volume has been reduced by digestion. At the time when eggs are maturing and host-seeking is inhibited, pre-oviposition behavior predominates if the central nervous system receives oviposition site stimuli. This behavior is also initiated by a humoral factor. Several physiological states, including insemination, age, and nutrition, can modulate both host-seeking and preoviposition behaviors.

Key words. Aedes aegypti; mosquito; behavior; host-seeking; pre-oviposition; reproduction; olfactometer; endocrinology.

\section{Introduction}

Among the numerous reasons for the success of insects is their ability to engage in relatively complex behaviors in spite of a simple nervous system that must operate under the constraints that a small body size imposes. This is possible because many of these stereotyped behaviors are genetically programmed into the central nervous system and are released by various exogenous or endogenous stimuli. The eclosion behavior of Lepidoptera is a wellunderstood example of this behavioral control mechanism, in which a neurosecretory peptide, eclosion hormone, acts directly on the nervous system to release motor patterns necessary for ecdysis ${ }^{171,174-176}$. The expression of this behavior may be modulated by endogenous factors that reflect the physiological state of the insect when the stereotyped behaviors may be biologically inappropriate ${ }^{136}$. The elegance of this system reflects the economy to which mechanisms controlling insect behavior have been forced to conform.

This review will attempt to summarize what is known about the role and identity of the endogenous factors that regulate the reproductive behavior of female mosquitoes. The discussion of reproductive behavior will be restricted to the endogenous regulation of two events that define the gonotrophic cycle, so named because of the relationship between feeding and reproduction, involving the behaviors that first allow the female mosquito to find a reproductive meal, and then to locate an aquatic site on which to lay the eggs that develop. The exogenous stimuli that initiate these behaviors, including various host odors and volatile components characteristic of oviposition sites, have been discussed elsewhere ${ }^{1,21,24,70,160}$ and will not be considered in this review. As with eclosion behavior in Lepidoptera, humoral factors appear to release programmed behaviors, the expression of which may be modulated by the physiological state of the mosquito.

Some mosquito species are autogenous and carry over adequate protein reserves from the larval stage that are used to mature their first egg batch. However, in the majority of species which are anautogenous, the ingestion of a blood meal is the only way the adult female can obtain sufficient protein for egg maturation. In order to first find a source of blood, it is necessary for the mosquito to engage in a series of behavioral programs collectively referred to as host-seeking, with blood ingestion or biting, influenced by a different series of cues, as the terminal step ${ }^{109}$. Roth ${ }^{152}$ emphasized the differences between host-seeking and biting by demonstrating that although removal of the antennae abolished hostseeking behavior, these same mosquitoes would bite if placed directly on the host. Host-seeking ordinarily occurs when the female perceives exogenous host stimuli ${ }^{1,12,21,24,70,109,160}$, but after blood is ingested the behavior is generally inhibited by endogenous factors until after the eggs are laid.

While the eggs are maturing and host-seeking behavior is suppressed, the female becomes more sensitive to oviposition site stimuli, and another behavioral program, preoviposition, is then initiated by endogenous substances when accompanied by exogenous stimuli from oviposi- 
tion sites. This change in her behavior from seeking a host to seeking an appropriate place for oviposition is necessary in order for this terrestrial adult to locate a suitable site for the future development and survival of the larvae. Because larvae are aquatic, their survival depends on the proper placement of eggs by the female. Oviposition behavior, consisting of egg deposition, appears to be governed by another series of cues involving close-range substrate recognition $2,38,90,156$. After the eggs are laid, pre-oviposition behavior is terminated and the female resumes host-seeking behavior in search of another source of protein for a subsequent batch of eggs.

Searching for blood and laying the eggs that are produced are events that define the beginning and end of the mosquito gonotrophic cycle. Depending on the longevity of the species, a female mosquito may complete from one to as many as thirteen cycles in her lifetime ${ }^{45}$. With each attempt to feed comes the possibility that a mosquito infected with a parasite may transmit it, and for this reason, the frequency of feeding is one important factor in establishing the vector status of a species. It has often been assumed that only one blood meal is ingested during each gonotrophic cycle, placing an upper limit on the number of times an individual female will ingest blood $^{129}$. Environmental conditions are probably most influential in modifying the expression of mosquito behavior ${ }^{10}$, and under certain conditions, multiple feeding during a single gonotrophic cycle may occur, which increases the opportunity for acquiring and transmitting pathogens $5,14,26$. Laboratory experiments have demonstrated that pathogen transmission may occur when two blood meals are ingested during a single gonotrophic cycle $^{107,133}$. Because the two behavioral events that define the gonotrophic cycle also influence the frequency of blood-feeding, it is essential that we first understand the mechanisms that regulate these behaviors if we ever hope to fully understand the role of mosquitoes as vectors.

\section{Endogenous regulation of host-seeking behavior}

Regulation of behavior after adult emergence. Mosquitoes reared under sub-optimal conditions as larvae fail to attain their potential maximum adult size ${ }^{178}$, and in the laboratory a significant proportion of these small adults also fail to engage in host-seeking behavior ${ }^{100,172}$. Of those mosquitoes that do seek a host, many may require two blood meals in order to mature a batch of eggs ${ }^{60}$. In the field, Nasci ${ }^{140,141}$ has shown that smaller mosquitoes are not well represented in blood-fed populations, and has suggested that these smaller adults are not as successful in obtaining a reproductive meal as are larger females.

There is usually a period of $1-2$ days after adult emergence during which host-seeking does not occur ${ }^{13,119}$. During this time, the corpora allata produce juvenile hormone, which stimulates ovarian development to the resting stage ${ }^{76}$ and makes several other tissues competent to respond to endocrine stimuli that ultimately lead to the later production of vitellogenin $61,151,162$ Allatectomy at adult emergence prevented egg development in Aedes aegypti, but did not affect biting ${ }^{113}$. However, allatectomy of Culex mosquitoes at emergence not only blocked the development of eggs, but also the development of post-emergence biting ${ }^{128}$. Allatectomy after the first blood meal also prevented the development of a second biting cycle ${ }^{126}$. The restoration of biting behavior when juvenile hormone was applied or active corpora allata were implanted suggested that juvenile hormone induced biting in Culex, although this mechanism was not evident in species of either Anopheles or Aedes ${ }^{16}$. The reasons for the differences among Culex and these other genera for the regulation of biting are not understood $^{127}$. In a review of mosquito diapause, Mitchell ${ }^{132}$ suggested that since Culex, unlike Aedes, diapause as adults, the allatectomy may have induced a diapause state characterized by the absence of biting.

A genetic component to mosquito host-seeking behavior $^{36,157,173}$ and host preference ${ }^{138}$ has been identified. Indeed, there is some evidence that population gene frequencies and the resulting feeding behavior of a population can be altered by the phenomenon of 'behavioristic avoidance' in which residual deposits of DDT cause an irritation that may induce mosquitoes to leave a treated area before absorbing a lethal dose 25,66 . However, this mechanism has also been downplayed as a selective pressure on mosquito populations ${ }^{137}$.

Regulation of behavior during adult reproductive diapause An adult reproductive diapause results when the immature stages of some species are exposed to shortened photoperiod and reduced temperatures $57,121,158,165$, allowing them to survive unfavorable winter conditions. The behavioral and physiological changes that distinguish these overwintering inseminated females include a reduced host-seeking and biting drive, gonotrophic dissociation or an ovarian diapause ${ }^{180}$, and fat body hypertrophy ${ }^{131,132}$. Ovarian diapause can be terminated ${ }^{164}$ and biting restored ${ }^{28,130}$ in these females with the topical application of juvenile hormone mimics. Bowen et al. ${ }^{18}$ showed that diapausing adult mosquitoes displayed a reduced host-seeking response and correlated the absence of this behavior with a reduction in the sensitivity of antennal lactic acid receptors.

Regulation of behavior by an endogenous circadian clock Mosquito behavior is often governed by an endogenous circadian clock. Most species of mosquitoes show the greatest activity atdusk and dawn $37,77,78,144,161,169,170$. Flight activity and the subsequent host-seeking are controlled by a circadian clock $^{35,85}$, but can be modified by blood ingestion and insemination ${ }^{86,153}$. Behaviors expressed during circadian activity windows can be influenced by the number of gonotrophic cycles the female 
has undergone $4,29,40,124$ and whether she is infected with parasites ${ }^{154,155}$.

\section{Regulation of behavior after feeding}

Although adult female mosquitoes require a protein meal for egg maturation, they can survive, but not reproduce, by ingesting carbohydrate. Carbohydrate is also the major source of energy for flight ${ }^{143}$. Nectar from flowers commonly serves as a food source in the field ${ }^{3,11,73}$, but abundant supplies of honeydew may also be impor$\operatorname{tant}^{46,91}$. General laboratory observations tend to support the contention that sugar feeding suppresses the subsequent tendency to feed on blood, but the data are conflicting. Clements ${ }^{34}$ suggested that the biting drive was independent of nectar feeding, while Christophers ${ }^{33}$ reported that sugar deprivation increased biting activity, supported by the studies of Jones and Madhukar ${ }^{84}$ who observed that sucrose ingestion reduced the responsiveness of Ae. aegypti to a human host. When given access to a $50 \%$ honey solution, Ae. aegypti were less likely to blood-feed, but Anopheles quadrimaculatus were not affected ${ }^{62}$.

Once a large blood meal is ingested, the host-seeking behavior of $A e$. aegypti is inhibited until eggs are laid. This behavioral inhibition can be attributed to at least two endogenous mechanisms. The first is dependent upon the midgut distention that occurs after a large blood meal and is referred to as distention-induced inhibition. The second mechanism, oocyte-induced inhibition, only results when egg development is initiated by the blood meal, and in Ae. aegypti, the behavioral inhibition is maintained until oviposition ${ }^{95}$.

Mosquitoes ingesting blood volumes below a critical threshold will continue to engage in host-seeking behavior but a behavioral inhibition results if they consume a meal above a certain volume $47,102,104,120,134$ (fig. 1). This critical threshold varies with body size; smaller adult females resulting from a sub-optimal larval diet have a lower threshold (fig. 1). All evidence points to an involvement of abdominal stretch receptors in the triggering of this distention-induced inhibition. Host-seeking inhibition results when volumes of saline or even air that are greater than the distention threshold are introduced into the midgut via the anus (fig. 2), and behavior can be manipulated by selectively reducing the distention in anterior or posterior abdominal segments ${ }^{104}$. The specific receptors associated with the behavioral inhibition have not been identified. Ventral nerve cord transection in the anterior abdominal segments, which isolates the receptors from the brain and affects other distentionmediated processes such as blood meal volume ${ }^{75}$ and diuresis $^{146,167}$, does not reduce host-seeking inhibition (Klowden, unpublished data). This suggests that the innervation of the stretch receptors may originate in the thoracic ganglia or from the stomatogastric nervous system. Although the immediacy of the inhibition suggests a neural mechanism, it is possible that neurohormones

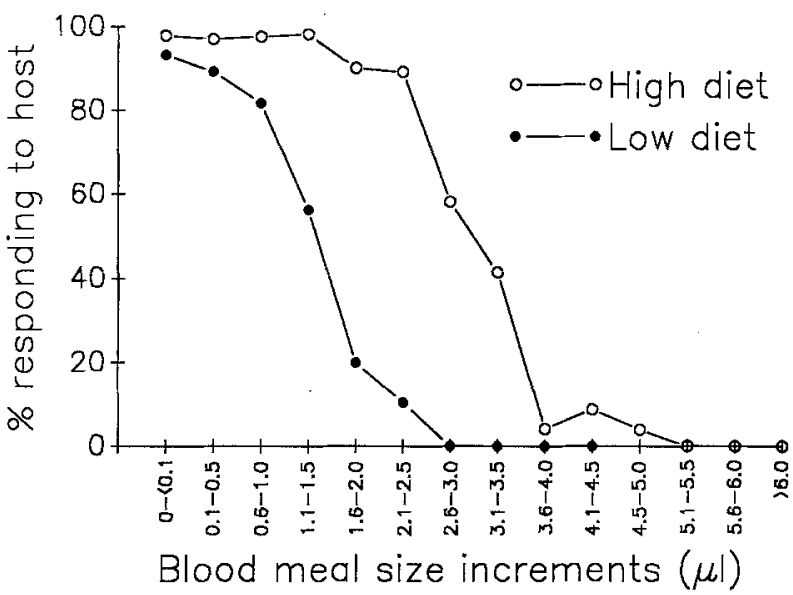

Figure 1. Effects of blood ingestion on the subsequent host-seeking behavior of Ae. aegypti females. Mosquitoes were reared on either a high or low larval diet, resulting in large or small adults, respectively. Blood volumes were grouped in half-microliter increments. Redrawn from Klowden and Lea ${ }^{102}$.

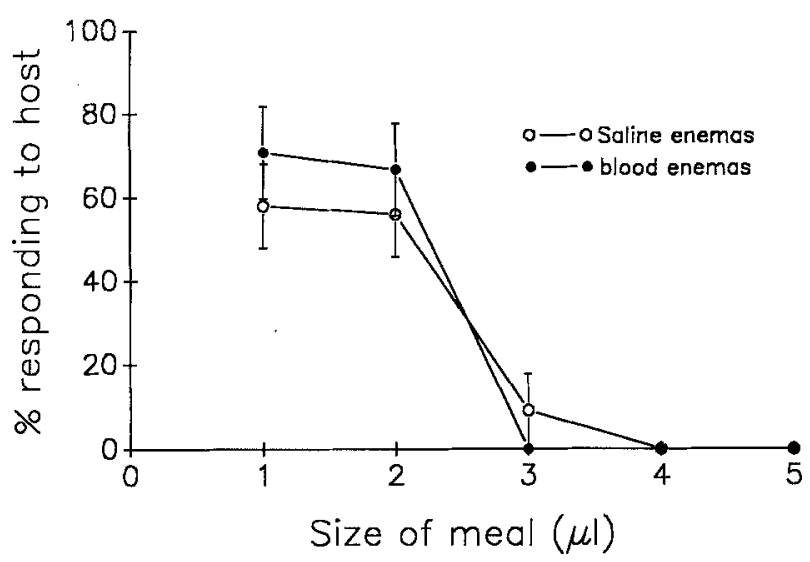

Figure 2. The host-seeking responses of Ae. aegypti mosquitoes given measured enemas of saline or blood. Vertical bars represent the standard errors. Redrawn from Klowden and Lea ${ }^{104}$.

released as a result of abdominal stretch might also be responsible. An example of this immediate release was recently provided by Lange et al. ${ }^{110}$, who demonstrated that serotonin is a neurohormone of uncertain function in the blood-sucking bug, Rhodnius prolixus, and is found in circulation within one minute after blood ingestion. Numerous endocrine cells are present in the midgut of Ae. aegypti $i^{23}$ and neurons within the ganglia of the head and ventral nerve cord have been shown to be immunoreactive to locust adipokinetic hormone and FMRF amide antisera ${ }^{22,123}$. It is tempting to speculate on the possible behavioral functions of these and other neuropeptides that could be immediately released by nervous signals from the abdomen.

Distention-induced inhibition is manifested for as long as the abdomen is distended, but eventually disappears as the blood meal is digested ${ }^{95}$. Feeding to repletion creates enough distention to inhibit Ae. aegypti until the second mechanism of oocyte-induced inhibition is initiated 


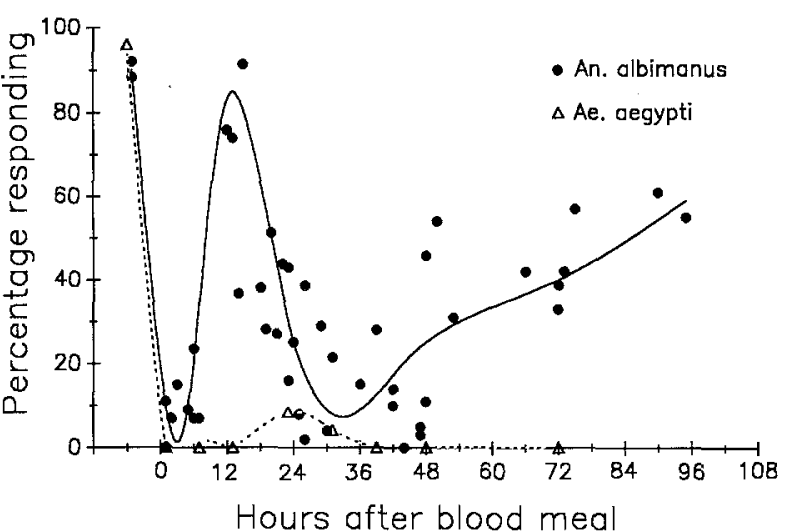

Figure 3. Host-seeking behavior of An. albimanus and Ae. aegypti after free-feeding on blood to repletion.

during egg development, but Anopheles albimanus, which has a smaller midgut capacity, will attempt to refeed sooner (fig. 3; Klowden and Briegel, unpublished data).

There is field evidence that blood-fed females may continue to engage in host-seeking behavior ${ }^{134,168}$. This departure from the physiological 'rules' that govern the behavior may be explained by at least two circumstances. First, given the defensive behavior displayed by many hosts that mosquitoes feed upon $42,43,48,50,51$, instances of multiple feeding may be the result of the failure to initially ingest enough blood to trigger distention-induced inhibition ${ }^{186}$. Second, the amount of distention and the rate at which it is reduced is related to aging. In Ae. aegypti, the host-seeking of older females is terminated after ingesting less blood than when they were younger as a consequence of an age-related reduction in their distention threshold ${ }^{106}$. However, the threshold is restored if these older mosquitoes have undergone at least one prior gonotrophic cycle. In these gonotrophically older females that have matured a prior egg batch, hostseeking behavior also returns more rapidly ${ }^{97}$. The rate at which the blood is digested by an older mosquito is also affected by whether she has completed a prior gonotrophic cycle ${ }^{19,20}$. Consequently, the older segment of a mosquito population, which is of the most epidemiological importance because of the increased opportunities for acquiring parasites, is apparently also the most likely to engage in multiple feeding.

After the blood meal has been digested and oogenesis has been initiated, oocyte-induced host-seeking inhibition suppresses the behavior of females. Because gravid females refrain from host-seeking in the field, sweep net and aspirator trapping generally recover a higher proportion of gravid females than do attractant traps ${ }^{9,166}$. Autogenous species, which do not require blood to mature their first batch of eggs, also show a reluctance to seek a host until the eggs have been deposited ${ }^{145}$. In laboratory tests, Ae. aegypti showed a significant decline in hostseeking at $30 \mathrm{~h}$ after blood ingestion, and between 48 and

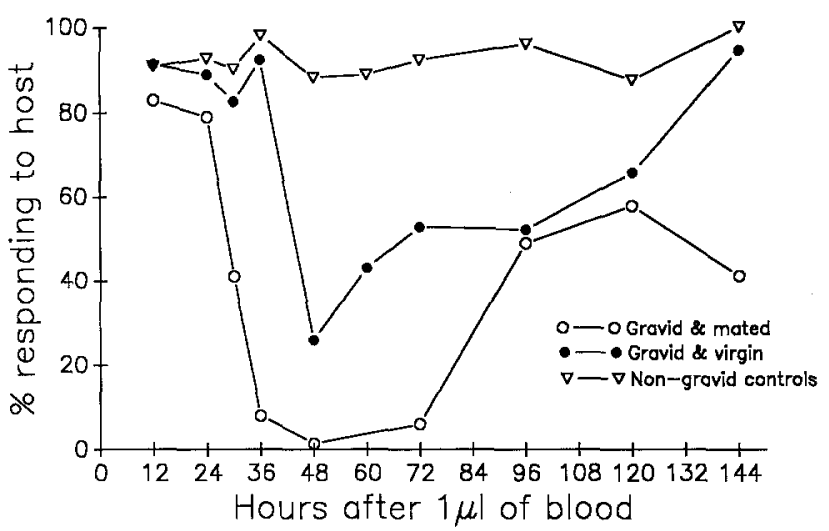

Figure 4. Host-seeking behavior of mated and virgin Ae. aegypti after a $1-\mu$ l enema of blood. Redrawn from Klowden and Lea ${ }^{103}$.

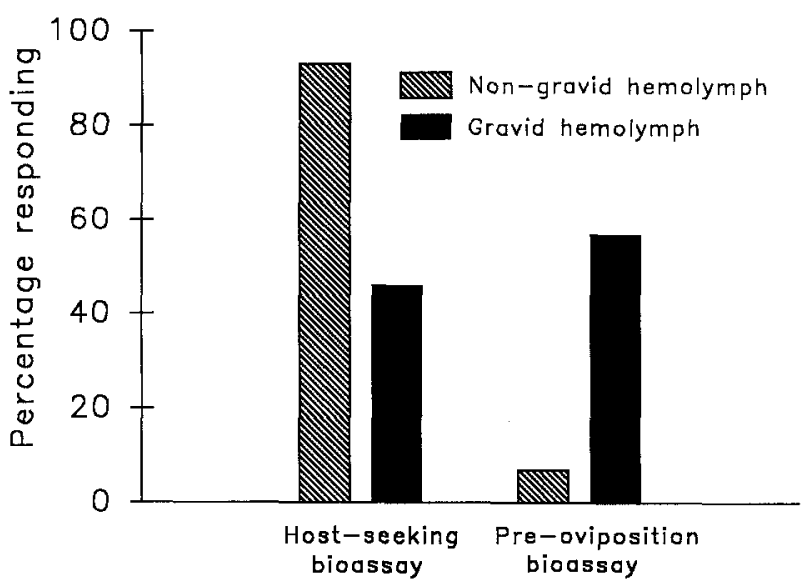

Figure 5. Effects of hemolymph transfusion on the behavior of nonblood-fed $A e$. aegypti. In the host-seeking bioassay, females received $0.5 \mu \mathrm{l}$ of hemolymph from gravid females at $48 \mathrm{~h}$ after they had fed on blood. In the pre-oviposition bioassay, females received $0.5 \mu \mathrm{l}$ of hemolymph from gravid females at $72 \mathrm{~h}$ after they had fed on blood. Redrawn from Klowden and Lea ${ }^{103}$ and Klowden and Blackmer ${ }^{100}$.

$72 \mathrm{~h}$, less than $10 \%$ of the gravid population respond$\mathrm{ed}^{103}$ (fig. 4). This second inhibition is not due to abdominal distention, but apparently occurs in response to a hemolymph-borne factor; hemolymph transfused from gravid insects inhibits the host-seeking behavior of nongravid females ${ }^{103}$ (fig. 5). The inhibition occurs by a two-step process: the maturing ovaries first activate the fat body which then appears to produce a behavioral inhibitor ${ }^{93,101}$. The inhibition is terminated by nervous signals associated with oviposition ${ }^{93}$.

Neither the ovarian factor nor the fat body factor has been identified. The ovaries of mosquitoes are known to be endocrine organs ${ }^{79,115}$ and it has been proposed that ovarian ecdysteroids directly suppress host-seeking behavior ${ }^{6}$. However, the doses of 20 -hydroxyecdysone that inhibited behavior were many times the endogenous levels, suggesting that the behavioral inhibition observed might have been artifactual ${ }^{92,94}$. More convincing is the possibility that ovarian ecdysteroids trigger the fat body 
to release its factor ${ }^{17}$. There are no other examples of the production of hormones by this tissue except for recent reports suggesting that the fat body of lepidopterans is a source of regulatory substances ${ }^{72,74,181}$.

The behavioral inhibitor appears to act on the peripheral sensory receptors that detect host stimuli, making them less sensitive. Vertebrates present a complex odor profile to mosquitoes, but only one component, lactic acid, has been examined in detail. The behavioral inhibition during oogenesis paralleled a decline in the sensitivity of antennal lactic acid receptors, and the sensitivity of these receptors in non-gravid mosquitoes was reduced by the transfusion of hemolymph from gravid mosquitoes ${ }^{41}$.

Although under laboratory conditions, oocyte-induced host-seeking inhibition effectively suppresses behavior in Ae. aegypti, there have been numerous reports in other species of host-seeking by gravid and previously bloodfed mosquitoes in the field ${ }^{71,119,124,139}$. Several physiological factors may explain this phenomenon.

Nutritional state appears to have the greatest effect in overriding the inhibition. Inadequate larval nutrition can result in double anautogeny in the adult, which requires two blood meals for juvenile hormone release and the maturation of a single batch of eggs ${ }^{60}$. This may have been the reason for what some investigators have called the 'pre-gravid' phase of Anopheles ${ }^{67-69,150}$. Inadequate adult nutrition can reduce the likelihood that a female will develop eggs from a given blood volume $49,96,142$. In either case, in the absence of egg development after a blood meal, there would be no behavioral inhibition once the abdominal distention was reduced. Moreover, nutritionally-deprived adult mosquitoes that do develop eggs appear to put less of their limited resources into the production of the behavioral inhibitor. When Ae. aegypti were maintained on only water and a small blood meal, almost $70 \%$ of those that developed eggs still responded to a host ${ }^{96}$.

Other factors can influence the extent of host-seeking inhibition. As discussed previously in the section on distention-induced inhibition, older mosquitoes show differences in their distention thresholds if they have not blood-fed previously. Older mosquitoes also show less oocyte-induced inhibition and are more likely to seek a host throughout their life cycle ${ }^{108}$. Whether or not a gravid female is inseminated also affects the extent of oocyte-induced host-seeking inhibition $89,103,112$ (fig. 4). The onset of host-seeking inhibition in a population of virgin $A e$ aegypti is delayed and a smaller proportion of the population is inhibited compared to mated females. This may allow for uninseminated females to return to the vicinity of a host for the purposes of mating, since male Ae. aegypti also aggregate near the host ${ }^{80}$.

The two endogenous mechanisms that inhibit host-seeking behavior, a behavior that is essential for reproduction, may have evolved with the selective pressure of host defensive behavior. Considering that the behavior of a host can pose a significant risk to a small insect attempt- ing to feed upon it it $^{42,50,52,53,105}$, it is not surprising that mosquito host-seeking would be limited only to periods that can enhance reproductive potential. Although fecundity is related to the size of the blood meal ${ }^{183}$, in $A e$. aegypti, once a small meal is ingested, a second blood meal that follows does not supplement the first if it occurs after $14 \mathrm{~h}^{114}$. Gravid mosquitoes that ingest another blood meal before their eggs are laid are unable to enhance their fecundity because an oostatic hormone inhibits the maturation of the remaining, less mature follicles 58,125 . Oostatic factors may also prevent the synthesis of trypsin which would limit the availability of precursors for yolk protein ${ }^{15}$.

The hypothesis that continued host-seeking and blood ingestion once oogenesis has commenced would not always be reproductively advantageous is strengthened by our recent experiments with the crepuscular feeder, $A n$. albimanus, which is more inclined than Ae. aegypti to seek a host following a blood meal (fig. 3; Klowden and Briegel, unpublished data). For a species like $A n$. albimanus, which has a smaller midgut capacity than $A e$. aegypti and which feeds at night on inactive hosts that display less host defensive behavior, there may have also been less of a selective pressure to develop a mechanism for inhibiting host-seeking behavior.

\section{Endogenous regulation of pre-oviposition behavior}

Another major change in behavior that favors reproduction following the ingestion of a blood meal is the initiation of pre-oviposition behavior, expressed as an increased response to oviposition site stimuli. Because the larval and adult habitats of mosquitoes differ, a mechanism must exist for re-programming the behavior of the gravid female in order to bring her to an environment suitable for her progeny before egg deposition can occur. Mosquito pre-oviposition behavior was first defined by Klowden and Blackmer ${ }^{99}$ and most of the work regarding the mechanisms that regulate this behavior have come from our laboratory.

Mosquito oviposition site stimuli have been partially identified $7,8,59,83,111,118,122,147$, but they cannot elicit pre-oviposition behavior unless the mosquito has eggs. Using pre-oviposition behavior as a criterion permitted the use of microsurgical techniques that did not prevent a mosquito from responding to site stimuli, but that might have interfered with oviposition behavior. The use of this behavior also made it possible to evaluate whether oviposition site stimuli influenced mosquitoes in the absence of egg development or even prior to ovulation. The mechanisms that regulate mosquito oviposition behavior have previously been examined using egg deposition as a criterion $^{65,81}$ and will not be considered here.

\section{Effects of egg development on pre-oviposition behavior} When $0.1 \%$ methyl propionate was used as an oviposition site stimulus for Ae. aegypti in a laboratory olfac- 


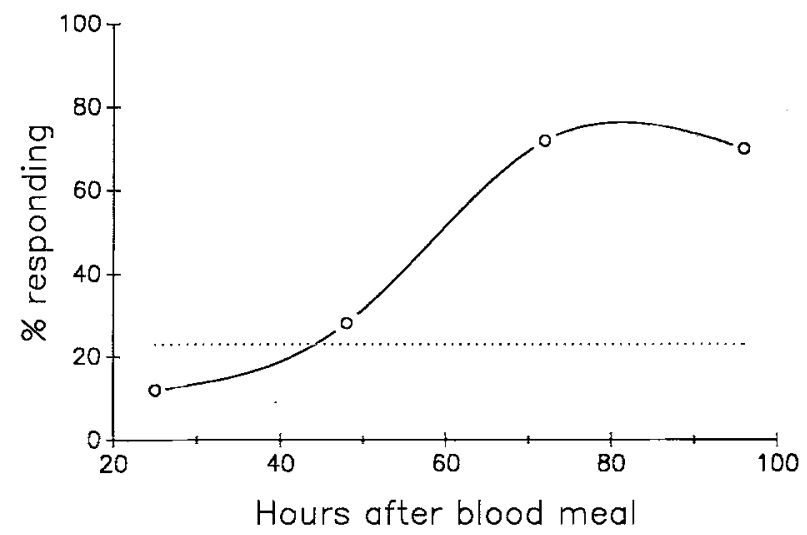

Figure 6. The behavior of gravid Ae. aegypti females in the pre-oviposition olfactometer. The dotted line represents the behavior of non-gravid controls. Redrawn from Klowden and Blackmer ${ }^{100}$.

tometer, initial tests demonstrated that the responses of gravid females significantly differed from non-gravid insects beginning at $72 \mathrm{~h}$ after blood was ingested ${ }^{99}$ (fig. 6). Therefore, Ae. aegypti pre-oviposition behavior was studied in females that had ingested blood at least $72 \mathrm{~h}$ before. They were placed in the olfactometer in the late afternoon, and their orientation towards the pre-oviposition stimulus was recorded the following morning.

Once this behavioral assay was established, the nature of the pre-oviposition control mechanism could be examined. It was first determined if pre-oviposition behavior was programmed to occur after blood was ingested or if mature ovaries were also required. Mosquitoes ovariectomized at emergence and fed blood did not engage in pre-oviposition behavior. However, if one of the ovaries was reimplanted before the blood meal, the response was restored even though the ovary was not innervated ${ }^{99}$, demonstrating an independence from the nervous system. Pre-oviposition behavior was also unrelated to the number of oocytes that matured, because mosquitoes receiving partial ovariectomies, in which only a small number of follicles were allowed to remain, still engaged in pre-oviposition behavior after blood ingestion. To establish whether or not pre-oviposition was triggered by a hemolymph-borne substance, hemolymph was transfused from gravid females into sugar-fed females. These transfusions induced a significant increase in pre-oviposition behavior compared to controls that received hemolymph from other non-gravid mosquitoes or those injected with saline ${ }^{99}$ (fig. 5). Implants of fat body from gravid females also induced pre-oviposition behavior in non-gravid recipients ${ }^{98}$. Thus, the two mechanisms that regulate host-seeking inhibition and pre-oviposition behavior apparently both involve an ovarian signal acting on the fat body. Preliminary experiments indicate that the pre-oviposition substance is inactivated by heat and trypsin, suggesting that it is a peptide. Pre-oviposition behavior, like host-seeking inhibition, is terminated by a nervous signal after oviposition occurs ${ }^{98}$.
Effects of mating on pre-oviposition behavior

In addition to spermatozoa, male mosquitoes contribute substances from the accessory reproductive gland during copulation. A successful insemination by the male and the introduction of these substances can change the behavior and physiology of the female, resulting in monogamy ${ }^{39}$, autogeny ${ }^{148}$, and altered circadian flight activity $^{87}$, in addition to the modifications of host-seeking behavior discussed previously. Virgin female $A e$. aegypti also do not ordinarily lay the eggs that develop from a blood meal ${ }^{179}$ but can be induced to do so if they are implanted with male accessory glands or their extracts $^{81,117}$. Fuchs and Kang ${ }^{65}$ postulated that the failure of virgin mosquitoes to oviposit was caused by an endogenous inhibitor that is inactivated by mating. The active component from the male accessory glands is reportedly a protein. In $C x$. tarsalis, its molecular weight is approximately $2 \mathrm{kDa}^{184}$, but in $A e$. aegypti, it has been described as consisting of 30 and $60 \mathrm{kDa}$ fractions $63,81,182$. When injected into virgin females, both fractions were necessary to prevent further insemination, but only one fraction enhanced oviposition ${ }^{64}$.

Gravid virgin Ae aegypti also fail to engage in pre-oviposition behavior (Yeh and Klowden, unpublished data). Gravid virgins implanted with a piece of trachea or a single testis still displayed the behavior pattern of virgins, but a significant increase in pre-oviposition behavior was observed when these females received a male accessory gland. Gland homogenates at concentrations as low as 0.02 gland equivalents increased pre-oviposition behavior significantly (Yeh and Klowden, unpublished data). Preliminary data suggest that the male accessory gland substance that acts on pre-ovipositon behavior is also a protein. Interspecific accessory gland implantations have demonstrated a non-specificity between several mosquito species for stimulating oviposition and mating inhibition $^{149}$, and even glands of Drosophila melanogaster are active in virgin $A e$. aegypti ${ }^{116}$. However, recent experiments have shown that glands of Ae. albopictus, Ae. taeniorhynchus, Ae. sierrensis, and An. nr. salbaii fail to induce pre-oviposition in gravid virgin Ae. aegypti (Yeh and Klowden, unpublished data), indicating that a specific component not shared by these other mosquito species is necessary for the expression of this behavior. Although previous reports demonstrated the activity of Drosophila male accessory glands in mosquitoes, Young and Downe ${ }^{185}$ were unable to find any cross-reactivity among the proteins present in the glands of $C x$. tarsalis and $D$. melanogaster. Within the genus Drosophila, male accessory gland components are fairly species-specific ${ }^{30}$, and interspecific gland implantations between non-sibling species fail to stimulate oviposition ${ }^{31}$. The active peptide from the Drosophila male has been isolated and sequenced $^{32}$. Monsma and Wolfner ${ }^{135}$ identified two genes expressed in the male accessory glands of $D$. melanogaster that are responsible for proteins transferred to the female during copulation and which are subse- 


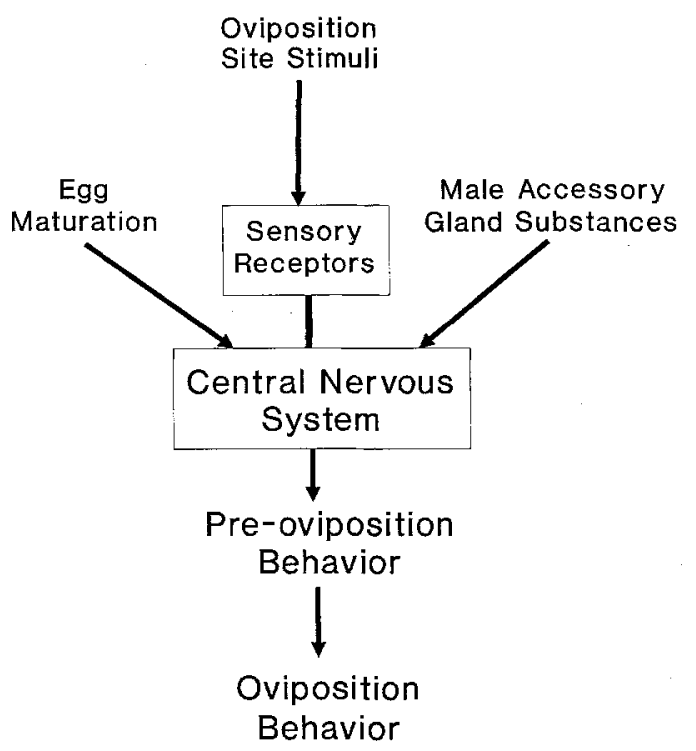

Figure 7. Model for the activation of pre-oviposition behavior. Female Ae. aegypti must receive exogenous information from the oviposition site, and also endogenous information that eggs are present and mating has occurred before pre-oviposition behavior is initiated.

quently altered within the female. The amino acid sequence of one male-derived protein resembles that of the egg-laying hormone produced by the mollusc Aplysia californica $^{159}$.

Thus, the female needs at least three pieces of information to initiate pre-oviposition behavior. She must have mature eggs, confirmed by the signal from the ovaries and fat body, she must be mated, verified by the presence of a male accessory gland factor, and her sensory receptors must tell her a suitable oviposition site is nearby, confirmed by the presence of volatile components and visual cues characteristic of these sites (fig. 7).

\section{Effects of nutritional state on pre-oviposition behavior}

Several studies have shown that sugar ingestion delays the oviposition of mature eggs in Culex and Aedes mosquitoes ${ }^{44,82,163}$. Pre-oviposition behavior was reduced significantly in sugar-fed gravid female Ae. aegyp$t i$, and the sugar also had an effect on the non-specific behavior of non-gravid females (Klowden and Dutro, unpublished data). By feeding equivalent volumes of different caloric meals and different calories of sucrose in equivalent volumes, it appeared that sucrose affected pre-oviposition behavior through abdominal distention (Klowden and Dutro, unpublished data).

\section{Population management using behavioral manipulation}

There may be some potential for using substances that can specifically alter mosquito behavior in a management program. This strategy might involve the expression or repression of reproductive behaviors at biologically inappropriate times in order to reduce the size of mosquito vector populations. This goal may not be a purely academic one, as there is at least one example of a mosquito parasite that has adopted this tactic. Egerter et al. ${ }^{55}$ found that $A e$. sierrensis females infected with the parasitic ciliate Lambornella clarki exhibited what appeared to be oviposition behavior, although the females had been parasitically castrated and had no eggs. Apparently, the ciliate induces pre-oviposition in the mosquito as a means of disseminating its own offspring. At the same time, the parasite also inhibits the host-seeking behavior of the mosquito ${ }^{54}$. In the carrot fly, Psila rosae, oviposition behavior was disrupted by fungal infection ${ }^{56}$. Egg development induces behavioral changes in a number of other insects $27,88,177$, but the mechanisms governing these changes are not well understood. It is conceivable that natural products could be identified that interfere with the behavior of many different insects and provide a specific means of controlling populations. After they are identified, the challenge will be to develop a method for introducing these substances into the target species.

Acknowledgments. The research from my laboratory was supported by grants AI-09410 (to Arden O. Lea) and AI- 24453 from the National Institutes of Health. I am grateful to H. Briegel, M. H. Hall, C. M. Smith, A. J. Klowden and T. M. Mowry for their editorial comments. Contribution number 89757 from the Idaho Agricultural Experiment Station.

1 Acree, F. Jr, Turner, R. B., Gouck, H. K., Beroza, M., and Smith, N., L-lactic acid: a mosquito attractant isolated from humans. Science 161 (1968) 1346-1347.

2 Adham, F. K., Studies on laboratory oviposition behavior of Aedes caspius (Diptera: Culicidae). Acta ent. bohem. 76 (1979) 99-103.

3 Andersson, I. H., and Jaenson, T. G. T., Nectar feeding by mosquitoes in Sweden, with special reference to $C$ ulex pipiens and $C x$ torrentium. Med. vet. Ent. 1 (1987) 59-64.

4 Aslam, Y., Reisen, W. K., and Aslamkhan, M., The influence of physiological age on the biting rhythm of Culex tritaeniorhynchus Giles (Diptera: Culicidae). S.E. Asian J. trop. Med. Publ. Hlth 8 (1977) 364-367.

5 Bang, F. B., and Reeves, W. C., Mosquitoes and encephalitis in the Yakima Valley, Washington. III. Feeding habits of Culex tarsalis Coq., a mosquito host of the viruses of western equine and St. Louis encephalitis. J. infect. Dis. 70 (1942) 273-274.

6 Beach, R., Mosquitoes: biting behavior inhibited by ecdysone. Science 205 (1979) 829-831.

7 Bentley, M. D., and Day, J. F., Chemical ecology and behavioral aspects of mosquito oviposition. A. Rev. Ent. 34 (1989) 401-421.

8 Bentley, M. D., McDaniel, I. N., and Davis, E. E., Studies of 4methylcyclohexanol: an Aedes triseriatus (Diptera: Culicidae) oviposition attractant. J. med. Ent. 19 (1982) 589-592.

9 Bidlingmayer, W. L., The influence of environmental factors and physiological stage on flight patterns of mosquitoes taken in the vehicle aspirator and truck, suction, bait and New Jersey light traps. J. med. Ent. 11 (1974) 119-146.

10 Bidlingmayer, W. L., The measurement of adult mosquito population changes-some considerations. J. Am. Mosq. Contr. Assoc. 1 (1985) 328-348.

11 Bidlingmayer, W. L., and Hem, D. G., Sugar feeding by Florida mosquitoes. Mosq. News 33 (1973) 535-538.

12 Bidlingmayer, W. L., and Hem, D. G., The range of visual attraction and the effect of competitive visual attractants upon mosquito (Diptera: Culicidae) flight. Bull ent. Res. 70 (1980) $321-342$.

13 Bishop, A., and Gilchrist, B. M., Experiments upon the feeding of Aedes aegypti through animal membranes with a view to applying this method to the chemotherapy of malaria. Parasitology 37 (1946) $85-100$.

14 Boreham, P. F. L., Lenahan, J. K., Boulzaguet, R, Storey, J., Ashkar, T. S., Nambiar, R., and Matsushima, T., Studies on multiple feeding by Anopheles gambiae s.l. in a Sudan savanna area north of Nigeria. Trans. Roy. Soc. trop. Med. Hyg. 73 (1979) 418-423. 
15 Borovsky, D., Oostatic hormone inhibits biosynthesis of midgut proteolytic enzymes and egg development in mosquitoes. Archs Insect Biochem. Physiol. 7 (1988) 187-210.

16 Bowen, M. F., and Davis, E. E., The effects of allatectomy and juvenile hormone replacement on the development of host-seeking behaviour and lactic acid receptor sensitivity in the mosquito Aedes aegypti. Med. vet. Ent. 3 (1989) 53-60.

17 Bowen, M. F., and Loess-Perez, S., A re-examination of the role of ecdysteroids in the development of host-seeking inhibition in blood fed Aedes aegypti mosquitoes, in: Host Regulated Developmenta Mechanisms in Vector Arthropods, pp. 286-291. Eds D. Borovsky and A. Spielman. Univ. Florida, Vero Beach 1989

18 Bowen, M. F., Davis, E. E., and Haggart, D. A., A behavioural and sensory analysis of host-seeking behavior in the diapausing mosquito Culex pipiens. J. Insect Physiol. 34 (1988) 805-813.

19 Briegel, H., Regulation of blood digestion in mosquitoes: effect of age of the female and the role of the neuroendocrine system in Aedes aegypti. Parasitology 82 (1981) 98-101

20 Briegel, H., Manipulation of age-dependent kinetics of the induction of intestinal trypsin in the mosquito Aedes aegypti (Diptera: Culicidae). Ent. gen. 8 (1983) 217-223.

21 Brown, A. W. A., Factors which attract Aedes mosquitoes to humans. Proc. 10th int. Congr. Entomol., Montreal 1956, 3 (1958) 757-763:

22 Brown, M. R., and Lea, A. O., FMRFamide- and adipokinetic hor mone-like immunoreactivity in the nervous system of the mosquito Aedes aegypti. J. comp. Neurol. 270 (1988) 606-614.

23 Brown, M. R., Raikhel, A. S., and Lea, A. O., Ultrastructure of midgut endocrine cells in the adult mosquito, Aedes aegypti. Tiss. Cell 17 (1985) 709-721.

24 Browne, S. M., and Bennett, G. F., Response of mosquitoes (Diptera: Culicidae) to visual stimuli. J. med. Ent. 18 (1981) 505521.

25 Bruce-Chwatt, L. J., Essential Malariology. William Heinemann Medical Books Ltd, London 1980.

26 Burkot, T. R., Graves, P. M., Paru, R., and Lagog, M., Mixed blood feeding by the malaria vectors in the Anopheles punctulatus complex (Diptera: Culicidae). J. med. Ent. 25 (1988) 205-213.

27 Campan, M., A study of the orientation behavior of Calliphora vomitoria (Diptera) females towards the odor of the oviposition site. Evidence of the role of the ovary. Gen. comp. Endocr. 31 (1977) $442-450$.

28 Case, T. J., Washino, R. K., and Dunn, R. L., Diapause termination in Anopheles freeborni with juvenile hormone mimics. Entomologia exp. appl. 21 (1977) 155-162.

29 Charlwood, J. D., Paru, R., Dagoro, H., and Lagog, M., Influence of moonlight and gonotrophic age on biting activity of Anopheles farauti (Diptera: Culicidae) from Papua New Guinea. J. med. Ent. 23 (1986) $132-135$.

30 Chen, P. S., and Balmer, J., Secretory proteins and sex peptides of the male accessory gland in Drosophila sechellia. J. Insect Physiol. 35 (1989) $759-764$

31 Chen, P.S., Stumm-Zollinger, E., and Caldelari, M., Protein metabolism of Drosophila male accessory glands. II. Speciesspecificity of secretion proteins. Insect Biochem. 15 (1985) 385-390.

32 Chen, P. S., Stumm-Zollinger, E., Aigaki, T., Balmer, J., Bienz, M. and Böhlen, $P$. ., A male accessory gland peptide that regulates reproductive behavior of female $D$. melanogaster. Cell 54 (1988) 291-298.

33 Christophers, S. R., Aëdes aegypti (L.). The Yellow Fever Mosquito. Cambridge University Press 1960.

34 Clements, A. L., The Physiology of Mosquitoes. Macmillan, NY 1963.

35 Clopton, J. R., Mosquito circadian flight rhythms: differential effects of constant light. Am. J. Physiol. 247 (1984) 960-967.

36 Coluzzi, M., Sabatini, A., Petrarca, V., and Di Deco, M. A., Behavioural divergences between mosquitoes with different inversion karyotypes in polymorphic populations of the Anopheles gambiae complex. Nature 266 (1977) 832-833.

37 Corbet, P.S., Diel patterns of mosquito activity in a high arctic locality: Hazen Camp, Ellesmere Island, N.W.T. Can. Ent. 98 (1966) $1238-1252$

38 Corbet, P. S., and Danks, H. V., Egg-laying habits of mosquitoes in the high arctic. Mosq. News 35 (1975) 8-14.

39 Craig, G. B. Jr, Mosquitoes: female monogamy induced by a male accessory gland substance. Science 156 (1967) 1499-1501.

40 Crans, W. J., Downing, J. D., and Slaff, M. E., Behavioral changes in the salt marsh mosquito, Aedes sollicitans, as a result of increased physiological age. Mosq. News 36 (1976) 437-445.
41 Davis, E. E., Regulation of sensitivity in the peripheral chemoreceptor systems for host-seeking behaviour by a haemolymph-borne factor in Aedes aegypti. J. Insect Physiol. 30 (1984) 179-183.

42 Day, J. F, and Edman, J. D., Mosquito engorgement on normally defensive hosts depends on host activity patterns. J. med. Ent. 21 (1984) $732-740$.

43 Day, J. F., Ebert, K. M., and Edman, J. D., Feeding patterns of mosquitoes (Diptera: Culicidae) simultaneously exposed to malarious and healthy mice, including a method for separating blood meals from conspecific hosts. J. med. Ent. 20 (1983) 120-127.

44 de Meillon, B., Sebastian, A., and Khan, Z. H., Cane-sugar feeding in Culex pipiens fatigans. Bull. W.H.O. 36 (1967) 53-65.

45 Detinova, T. S., Age-grouping methods in Diptera of medical importance. W.H.O. Monograph Series No. 47 (1962) 216 pp.

46 Downes, W. L. Jr, and Dahlem, G. A., Keys to the evolution of Diptera: role of Homoptera. Envir. Ent. 16 (1987) 847-854.

47 Edman, J. D., Cody, E., and Lynn, H., Blood-feeding activity of partially engorged Culex nigripalpus (Diptera: Culicidae). Entomologica exp. appl. 18 (1975) 261-268.

48 Edman, J. D., Day, J. F., and Walker, E. D., Field confirmation of laboratory observations on the differential antimosquito behavior of herons. The Condor 86 (1984) $91-92$.

49 Edman, J. D., and Lynn, H. C., Relationship between blood meal volume and ovarian development in Culex nigripalpus (Diptera: Culicidae). Entomologica exp. appl. 18 (1975) 492-496.

50 Edman, J. D., and Kale, II, H. W. Host behavior: its influence on the feeding success of mosquitoes. Ann. ent. Soc. Am. 64 (1971) 513-516.

51 Edman, J. D., and Scott, T. W., Host defensive behaviour and the feeding success of mosquitoes. Insect Sci. Applic. 8 (1987) 617-622

52 Edman, J. D., Webber, L. A., and Kale, II. H. W., Effect of mosquito density on the interrelationship of host behavior and mosquito feeding success. Am. J. trop. Med. Hyg. 21 (1972) 487-491.

53 Edman, J. D., Webber, L. A., and Schmid, A. A., Effect of host defenses on the feeding pattern of Culex nigripalpus when offered a choice of blood sources. J. Parasit. 60 (1974) 874-883.

54 Egerter, D. E., and Anderson, J. R., Blood-feeding drive inhibition of Aedes sierrensis (Diptera: Culicidae) induced by the parasite Lambornella clarki (Cilophora: Tetrahymenidae). J. med. Ent. 26 (1989) 46-54.

55 Egerter, D. E., Anderson, J. R., and Washburn, J. O., Dispersal of the parasitic ciliate Lambornella clarki: implications for ciliates in the biological control of mosquitoes. Proc. natl Acad. Sci. USA 83 (1986) $7335-7339$.

56 Eilenberg, J., Abnormal egg-laying behavior of female carrot flies (Psila rosae) induced by the fungus Entomopthora muscae. Entomologica exp. appl. 43 (1987) 61-65.

57 Eldridge, B. F., The effect of temperature and photoperiod on bloodfeeding and ovarian development in mosquitoes of the Culex pipiens complex. Am. J. trop. Med. Hyg. 17 (1968) 133-140.

58 Else, J. G., and Judson, C. L., Enforced egg retention and its effects on vitellogenesis in the mosquito, Aedes aegypti. J. med. Ent. 9 (1972) $527-530$.

59 Fay, R. W., and Perry, A. S., Laboratory studies of ovipositional preferences of Aedes aegypti. Mosq. News 25 (1965) 276-281.

60 Feinsod, F. M., and Spielman, A., Nutrient-mediated juvenile hormone secretion in mosquitoes. J. Insect Physiol. 26 (1980) 113-117.

61 Flanagan, T. R., and Hagedorn, H. H., Vitellogenin synthesis in the mosquito: the role of juvenile hormone in the development of responsiveness to ecdysone. Physiol. Ent. 2 (1977) 173-178.

62 Foster, W. A., and Eischen, F. A., Frequency of blood-feeding in relation to sugar availability in Aedes aegypti and Anopheles quadrimaculatus (Diptera: Culicidae). Ann. ent. Soc. Am. 80 (1987) 103 108.

63 Fuchs, M. S., Craig, G. B. Jr, and Despommier, D. D., The protein nature of the substance inducing female monogamy in Aedes aegypti. J. Insect Physiol. 15 (1969) $701-709$.

64 Fuchs, M. S., and Hiss, E. A., The partial purification and separation of the protein components of matrone from Aedes aegypti. I Insect Physiol. 16 (1970) 931-939.

65 Fuchs, M. S., and Kang, S.-H., Evidence for a năturally occurring inhibitor of oviposition in Aedes aegypti. Ann. ent. Soc. Am. 71 (1978) 473-475

66 Gerold, J. L., and Laarman, J. J., Selection of some strains of Anopheles atroparvus with different behavioural responses to contacts with DDT. Nature 204 (1964) 500-501.

67 Gillies, M. T., The recognition of age-groups within populations of Anopheles gambiae by the pre-gravid rate and the sporozoite rate. Ann. trop. Med. Parasit. 48 (1954) 58-74. 
68 Gillies, M. T., The pre-gravid phase of ovarian development in Anopheles funestus. Ann. trop. Med. Parasit. 49 (1955) 320-325.

69 Gillies, M. T., and Wilkes, T. J., A study of the age-composition of populations of Anopheles gambiae Giles and A. funestus Giles in north-eastern Tanzania. Bull. ent. Res. 56 (1965) 237-262.

70 Gillies, M. T., The role of carbon dioxide in host-finding by mosquitoes (Diptera: Culicidae): a review. Bull. ent. Res. 70 (1980) $525-532$.

71 Gould, D. J., Mount, G. A., Scanlon, J. E., Ford, H. R., and Sullivan, M. F., Ecology and control of dengue vectors on an island in the Gulf of Thailand. J. med. Ent. 7 (1970) 499-508.

72 Gray, R., Meola, R., and Holman, G. M., Fat body stimulation of ecdysone synthesis in Heliothis zea. J. Insect Physiol. 33 (1987) 325331.

73 Grimstad, P. R., and DeFoliart, G. R., Nectar sources of Wisconsin mosquitoes. J. med. Ent. 11 (1974) 331-341.

74 Gruetzmacher, M. C., Gilbert, L. I., and Bollenbacher, W. E., Indirect stimulation of the prothoracic glands of Manduca sexta by juvenile hormone: evidence for a fat body stimulatory factor. I Insect Physiol. 30 (1984) $771-778$

75 Gwadz, R. W., Regulation of blood meal size in the mosquito. I Insect Physiol. 15 (1969) 2039-2044

76 Gwadz, R. W., and Spielman, A., Corpus allatum control of ovarian development in Aedes aegypti. J. Insect Physiol. 19 (1973) $1441-$ 1448 .

77 Haddow, A. J., Studies on the biting-habits of African mosquitos. An appraisal of methods employed, with special reference to the twenty-four-hour catch. Bull. ent. Res. 45 (1954) 199-242.

78 Haddow, A J Observations on the biting habits of mosquitos in the forest canopy at Zika, Uganda, with special reference to the crepuscular periods. Bull. ent. Res. 55 (1964) 589-608

79 Hagedorn, H. H., O'Connor, J. D., Fuchs, M. S., Sage, B., Schlaeger, D. A., and Bohm, M. K., The ovary as a source of $\alpha$ ecdysone in an adult mosquito. Proc. natl Acad. Sci. USA 72 (1975) $3255-3259$

80 Hartberg, W. K., Observations on the mating behavior of Aedes aegypti in nature. Bull. W.H.O. 45 (1971) $847-850$

81 Hiss, E. A., and Fuchs, M. S., The effect of matrone on oviposition in the mosquito, Aedes aegypti. J. Insect Physiol. 18 (1972) $2217-$ 2227.

82 Hudson, A., Factors affecting egg maturation and oviposition by autogenous Aedes atropalpus. Can. Ent. 102 (1970) $939-949$

83 Hudson, B. N. A., The behaviour of the female mosquito in selecting water for oviposition. J. exp. Biol. 33 (1956) 478-492.

84 Jones, J. C., and Madhukar, B. V., Effects of sucrose on blood avidity in mosquitoes. J. Insect Physiol. 22 (1976) 357-360.

85 Jones, M. D. R., Coupled oscillators controlling circadian flight activity in the mosquito, Culex pipiens quinquefasciatus. Physiol. Ent 7 (1982) 281-289.

86 Jones, M. D. R., and Gubbins, S. J., Changes in the circadian flight activity of the mosquito Anopheles gambiae in relation to insemina tion, feeding and oviposition. Physiol. Ent. 3 (1978) 213-220.

87 Jones, M. D. R., and Gubbins, S. J., Modification of circadian flight activity in the mosquito Anopheles gambiae after insemination. $\mathrm{Na}$ ture 268 (1977) $731-732$

88 Juberthie, C., and Caussanel, C., Release of brain neurosecretory products from the neurohaemal part of the aorta during egg-laying and egg-care in Labidura riparia (Insecta, Dermoptera). J. Insect Physiol. 26 (1980) 427-429.

89 Judson, C. L., Feeding and oviposition behavior in the mosquito Aedes aegypti (L.). I. Preliminary studies of physiological contro mechanisms. Biol. Bull. 133 (1967) 369-377

90 Kennedy, J.S., Water-finding and oviposition by captive mosquitoes. Bull. ent. Res. 32 (1941) 279-301.

91 Killick-Kendrick, R., and Killick-Kendrick, M., Honeydew of aphids as a source of sugar for Phlebotomus ariasi. Med. vet. Ent. 1 (1987) 297-302.

92 Klowden, M. J., Large doses of ecdysterone may inhibit mosquito behavior nonspecifically. Science 208 (1980) 1062-1063.

93 Klowden, M. J., Initiation and termination of host-seeking inhibition in Aedes aegypti during oocyte maturation. J. Insect Physiol. 27 (1981) 799-803.

94 Klowden, M. J., Nonspecific effects of large doses of 20-hydroxyecdysone on the behavior of Aedes aegypti. Mosq. News 42 (1982) $184-189$.

95. Klowden, M. J., The physiological control of mosquito host-seeking behavior, in: Current Topics in Vector Research, vol. 1, pp. 93-116. Ed. K. F. Harris. Praeger Publishers, New York 1983.
96 Klowden, M. J, Effect of sugar deprivation on the host-seeking behaviour of gravid Aedes aegypti mosquitoes. J. Insect Physiol. 32 (1986) 479-483.

97 Klowden, M. J., Factors influencing multiple host contacts by mosquitoes during a single gonotrophic cycle. Misc. Publ. ent. Soc Am. 68 (1988) 29-36.

98 Klowden, M. J., Influence of the ovaries and fat body on the initiation and termination of pre-oviposition behavior in the mosquito, Aedes aegypti. J. Insect Physiol. 35 (1989) 567-570.

99 Klowden, M. J., and Blackmer, J. L., Humoral control of pre-oviposition behavior in the mosquito, Aedes aegypti. J. Insect Physiol. 33 (1987) $689-692$.

100 Klowden, M. J., Blackmer, J. L., and Chambers, G. M., Effects of larval nutrition on the host-seeking behavior of adult Aedes aegypti mosquitoes. J. Am Mosq. Contr. Assoc. 3 (1988) 73-75.

101 Klowden, M. J., Bowen, M. F., and Davis, E. E., Role of the fat body in the control of host-seeking behavior in the mosquito, Aedes aegypti. J. Insect Physiol. 33 (1987) 643-646.

102 Klowden, M. J., and Lea, A. O., Blood meal size as a factor affecting continued host-seeking by Aedes aegypti (L.). Am. I. trop. Med. Hyg. 27 (1978) 827-831

103 Klowden, M. J., and Lea, A. O., Humoral inhibition of host-seeking in Aedes aegypti during oocyte maturation. J. Insect Physiol. 25 (1979) $231-235$.

104 Klowden, M. J., and Lea, A. O., Abdominal distention terminates subsequent host-seeking behaviour of Aedes aegypti following a blood meal. J. Insect Physiol. 25 (1979) 583-585.

105 Klowden, M. J., and Lea, A. O., Effect of defensive host behavior on the blood meal size and feeding success of natural populations of mosquitoes (Diptera: Culicidae). J. med. Ent. 15 (1979) 514-517.

106 Klowden, M. J., and Lea, A. O., 'Physiologically old' mosquitoes are not necessarily old physiologically. Am. J. trop. Med. Hyg. 29 (1980) $1460-1464$

107 Klowden, M. J., and Lea, A. O., Laboratory transmission of Brugia pahangi by nulliparous Aedes aegypti (Diptera: Culicidae). J. med. Ent. 18 (1981) 383-385.

108 Klowden, M. J., and Lea, A. O., Blood feeding affects age-related changes in the host-seeking behavior of Aedes aegypti (Diptera: Culicidae) during oocyte maturation. J. med. Ent. 21 (1984) 274 277.

109 Laarman, J. J., The host-seeking behaviour of the malaria mosquito Anopheles maculipennis atroparvus. Acta leidensia 25 (1955) 1-144.

110 Lange, A. B., Orchard, I., and Barrett, F. M., Changes in haemolymph serotonin levels associated with feeding in the bloodsucking bug, Rhodnius prolixus. J. Insect Physiol. 35 (1989) 393-399.

111 Laurence, B. R., and Pickett, J. A., An oviposition attractant pheromone in Culex quinquefasciatus Say (Diptera: Culicidae). Bull. ent. Res. 75 (1985) 283-290.

112 Lavoipierre, M. M. J., Presence of a factor inhibiting biting in Aedes aegypti. Nature 182 (1958) 1567-1568.

113 Lea, A. O., Some relationships between environment, corpora allata and egg maturation in aedine mosquitoes. J. Insect Physiol. 9 (1963) $793-809$

114 Lea, A. O., Briegel, H., and Lea, H. M., Arrest, resorption, or maturation of oocytes in Aedes aegypti: dependence on the quantity of blood and the interval between blood meals. Physiol. Ent. 3 (1978) $309-316$.

115 Lea, A. O., and Van Handel, E., A neurosecretory hormone-releasing factor from ovaries of mosquitoes fed blood. J. Insect Physiol. 28 (1982) $503-508$

116 Leahy, M. G., Non-specificity of the male factor enhancing egg-laying in Diptera. J. Insect Physiol. 13 (1967) 1283-1292.

117 Leahy, M. G., and Craig, G. B. Jr, Accessory gland substance as a stimulant for oviposition in Aedes aegypti and A. albopictus. Mosq. News 25 (1965) 448-452.

118 Lounibos, L. P., Mosquito breeding and oviposition stimulant in fruit husks. Ecol. Ent. 3 (1978) 299-304.

119 Macdonald, W. W., Aedes aegypit in Malaya. II. Larval and adult biology. Ann. trop. Med. Parasit. 50 (1956) 399-414.

120 Magnarelli, L. A., Physiological age of mosquitoes (Diptera: Culicidae) and observations on partial blood-feeding. J. med. Ent. 13 (1977) 445-450.

121 Magnarelli, L. A Blood-feeding and gonotrophic dissociation in Anopheles punctipennis (Diptera: Culicidae) prior to hibernation in Connecticut. J. med. Ent. 15 (1979) 278-281.

122 Maire, A., and Langis, R., Oviposition responses of Aedes (Ochlerotatus) communis (Diptera: Culicidae) to larval holding water. J. med. Ent. 22 (1985) $111-112$ 
123 Matsumoto, S., Brown, M. R., Crim, J. W., Vigna, S. R., and Lea, A. O., Isolation and primary structure of neuropeptides from the mosquito Aedes aegypti, immunoreactive to FMRFamide antiserum. Insect Biochem. 19 (1989) 277-283.

124 McCrae, A. W. R., Age-composition of man-biting Aedes (Stegomyia) simpsoni (Theobald) (Diptera: Culicidae) in Bwamba County, Uganda. J. med. Ent. 9 (1972) 545-550.

125 Meola, R., and Lea, A. O., Humoral inhibition of egg development in mosquitoes. J. med. Ent. 9 (1972) 99-103.

126 Meola, R., and Readio, J., Juvenile hormone regulation of the second biting cycle in Culex pipiens. J. Insect Physiol. 33 (1987) 751 754.

127 Meola, R., and Readio, J., Juvenile hormone regulation of biting behavior and egg development in mosquitoes, in: Advances in Disease Vector Research, pp. 1-24. Ed. K. F. Harris. Springer-Verlag, New York 1988

128 Meola, R. W., and Petralia, R. S., Juvenile hormone induction of biting behavior in Culex mosquitoes. Science 209 (1980) 1548-1550.

129 Milby, M. M., and Reisen, W. K., Estimation of vectorial capacity: vector survivorship. Bull. Soc. Vect. Ecol. 14 (1989) 47-54.

130 Mitchell, C. J., Diapause termination, gonoactivity, and differentiation of host-seeking behavior from blood-feeding behavior in hibernating Culex tarsalis (Diptera: Culicidae). J. med. Ent. 18 (1981) $386-394$.

131 Mitchell, C. J., Differentiation of host-seeking behavior from bloodfeeding behavior in overwintering Culex pipiens (Diptera: Culicidae) and observations on gonotrophic dissociation. J. med. Ent. 20 (1983) 157-163.

132 Mitchell, C. J., Occurrence, biology, and physiology of diapause in overwintering mosquitoes, in: The Arboviruses: Epidemiology and Ecology, pp. 192-217. Ed. T. P. Monath. CRC Press Inc Boca Raton, Florida 1988.

133 Mitchell, C. J Bowen, S. G., Monath, T. P., Cropp, C. B, and Kerschner, J., St. Louis encephalitis virus transmission following multiple feeding of Culex pipiens pipiens (Diptera: Culicidae) during a single gonotrophic cycle. J. med. Ent. 16 (1979) 254-258.

134 Mitchell, C. J., and Millian, K. Y. Jr, Continued host-seeking by partially engorged Culex tarsalis (Diptera: Culicidae) collected in nature. J. med. Ent. 18 (1981) 249-250.

135 Monsma, S. A., and Wolfner, M. F., Structure and expression of a Drosophila male accessory gland gene whose product resembles a peptide pheromone precursor. Genes Devel. 2 (1988) 1063-1073.

136 Morton, D. B., and Truman, J. W., The EGPs: the eclosion hormone and cyclic GMP-regulated phosphoproteins. I. Appearance and partial characterization in the CNS of Manduca sexta. J. Neurosci. 8 (1988) 1326-1337.

137 Muirhead-Thomson, R. C., The significance of irritability, behaviouristic avoidance and allied phenomena in malaria eradication. Bull. W.H.O. 22 (1960) $721-734$.

138 Mukwaya, L. G., Genetic control of feeding preferences in the mosquitoes Aedes (Stegomyia) simpsoni and aegypti. Physiol. Ent. 2 (1977) 133-145.

139 Muul, I., Johnson, B. K., and Harrison, B. A., Ecological studies of Culiseta melanura (Diptera: Culicidae) in relation to eastern and western equine encephalomyelitis virus on the eastern shore of Maryland. J. med. Ent. 11 (1975) 739-748.

140 Nasci, R. S., Relationship between adult mosquito (Diptera: Culicidae) body size and parity in field populations. Envir. Ent. 15 (1986) $874-876$

141 Nasci, R. S., The size of emerging and host-seeking Aedes aegypti and the relation of size to blood-feeding success in the field. J. Am. Mosq. Contr. Assoc. 2 (1986) 61-62

142 Nayar, J. K., and Sauerman, D. M. Jr, The effects of nutrition on survival and fecundity in Florida mosquitoes. Part 3. Utilization of blood and sugar for fecundity. J. med. Ent. 12 (1975) 220-225

143 Nayar, J. K., and Van Handel, E., The fuel for sustained mosquito flight. J. Insect Physiol. 17 (1971) 471-481.

144 Nelson, M. J., Self, L. S., Pant, C. P., and Usman, S., Diurnal periodicity of attraction to human bait of Aedes aegypti (Diptera: Culicidae) in Jakarta, Indonesia. J. med. Ent. 14 (1978) 504-510.

145 Nelson, R. L., and Milby, M. M., Autogeny and blood-feeding by Culex tarsalis (Diptera: Culicidae) and the interval between oviposition and feeding. Can. Ent. 114 (1982) 515-521.

146 Nijhout, H. F., and Carrow, G. M., Diuresis after a bloodmeal in female Anopheles freeborni. J. Insect Physiol. 24 (1978) 293-298.

147 O'Gower, A. K., Environmental stimuli and the oviposition behaviour of Aedes aegppti var. queenslandis Theobald (Diptera: Culicidae). Anim. Behav. 11 (1963) 189-197.
148 O'Meara, G. F., and Evans, D. G., The influence of mating on autogenous egg development in the mosquito, Aedes taeniorhynchus. J. Insect Physiol. 22 (1976) 613-617.

149 Ramalingham, S., and Craig, G. B., Functions of the male accessory gland secretions of Aedes mosquitoes (Diptera: Culicidae): transplantation studies. Can. Ent. 108 (1976) 955-960.

150 Reisen, W. K., and Mahmood, F., Anopheles culicifacies Giles: some relationships among oviposition, refeeding and survivorship. Mosq. News 39 (1979) 374-381.

151 Rossignol, P., Spielman, A., and Jacobs, M. S., Rough endoplasmic reticulum in midgut cells of mosquitoes (Diptera: Culicidae): aggregation stimulated by juvenile hormone. J. med. Ent. 19 (1982) 719 721.

152 Roth, L. M., Loci of sensory end-organs used by mosquitoes (Aedes aegypti (L.) and Anopheles quadrimaculatus Say) in receiving host stimuli. Ann. ent. Soc. Am. 44 (1951) 59-74.

153 Rowland, M., Changes in the circadian flight activity of the mosquito Anopheles stephensi associated with insemination, bloodfeeding, oviposition and nocturnal flight intensity. Physiol. Ent. 14 (1989) $77-84$

154 Rowland, M., and Boersma, E., Changes in the spontaneous flight activity of the mosquito Anopheles stephensi by parasitization with the rodent malaria Plasmodium yoelii. Parasitology 97 (1988) 221 227.

155 Rowland, M. W., and Lindsay, S. L., The circadian flight activity of Aedes aegypti parasitized with the filarial nematode Brugia pahangi. Physiol. Ent. 11 (1986) 325-334.

156 Russo, R., Substrate texture as an oviposition stimulus for Aedes vexans (Diptera: Culicidae). J. med. Ent. 15 (1978) 17-20.

157 Rutledge, L. C., Khan, A. A., Skidmore, D. L., and Maibach, H. I., Genetic transmission of host-seeking behavior in colonized Aedes aegypti (L.). Mosq. News 35 (1975) 189-194.

158 Sandburg, L. L., and Larsen, J. R., Effect of photoperiod and temperature on ovarian development in Culex pipiens pipiens. J. Insect Physiol. 19 (1973) 1173-1190.

159 Scheller, R. H. Jackson, J. F. McAllister, L. B, Rothman, B. S, Mayeri, E., and Axel, R., A single gene encodes multiple neuropeptides mediating a sterotyped behavior. Cell 32 (1983) 7-22.

160 Schreck, C. E., Smith, N., Carlson, D. A., Price, G. D., Haile, D., and Godwin, D. R., A material isolated from human hands that attracts female mosquitoes. J. chem. Ecol. 8 (1981) 429-438.

161 Senior White, R. A., On the evening biting activity of three neotropical Anopheles in Trinidad, British West Indies. Bull. ent. Res. 44 (1953) $451-460$.

162 Shapiro, J. P., and Hagedorn, H. H., Juvenile hormone and the development of ovarian responsiveness to a brain hormone in the mosquito, Aedes aegypti. Gen. comp. Endocr. 46 (1982) 176-183.

163 Shroyer, D. A., and Sanders, D. P., The influence of carbohydratefeeding and insemination on oviposition of an Indiana strain of Aedes vexans (Diptera: Culicidae). J. med. Ent. 14 (1977) 121-127.

164 Spielman, A., Effect of synthetic juvenile hormone on ovarian diapause of Culex pipiens mosquitoes. J. med. Ent. 11 (1974) 223-225.

165 Spielman, A., and Wong, J., Environmental control of ovarian diapause in Culex pipiens mosquitoes. Ann. ent. Soc. Am. 66 (1973) 905-907.

166 Standfast, H. A., A miniature light trap which automatically segregates the catch into hourly samples. Mosq. News 32 (1965) 48-53.

167 Stobbart, R. H., The control of the diuresis following a blood meal in females of the yellow fever mosquito Aedes aegypti (L.). J. exp. Biol. 69 (1977) 53-85.

168 Sun, W. K. C., The seasonal succession of mosquitoes in Taiwan. J. med. Ent. 1 (1964) $277-284$.

169 Taylor, B., and Jones, M. D. R., The circadian rhythm of flight activity in the mosquito Aedes aegypti $(\mathrm{L}$.): the phase setting effects of light-on and light-off. J. exp. Biol. 51 (1969) 59-70.

170 Taylor, D. M., Bennett, G. F., and Lewis, D. J., Observations on the host-seeking activity of some Culicidae in the Tantramar marshes, New Brunswick. J. med. Ent. 15 (1979) 134-137.

171 Terzi, G., Truman, J. W. and Reynolds, S. E., Purification and characterization of eclosion hormone from the moth, Manduca sexta. Insect Biochem. 18 (1988) 701-707.

172 Terzian, L. A., and Stahler, N., The effects of larval population density on some laboratory characteristics of Anopheles quadrimaculatus Say. J. Parasit. 35 (1949) 487-495.

173 Trpis, M., and Hausermann, W., Genetics of house-entering behaviour in East African populations of Aedes aegypti (L.) (Diptera: Culicidae) and its relevance to speciation. Bull. ent. Res. 68 (1978) $521-532$. 
174 Truman, J. W., Development and hormonal release of adult behavior patterns in silk moths. J. comp. Physiol. 107 (1976) 39-48.

175 Truman, J. W., and Morton, D. B., The mechanism of steroid regulation of peptide action on the insect nervous system, in: Molecular Entomology, pp. 165-177. Ed. J. H. Law. Alan R. Liss, Inc., New York 1987.

176 Truman, J. W., and Riddiford, L. M., Neuroendocrine control of ecdysis in silkmoths. Science 167 (1970) 1624-1626.

177 Tyndale-Biscoe, M., Effects of ovarian condition on nesting behaviour in a brood-caring dung beetle, Copris diversus (Waterhouse (Coleoptera: Scarabaeidae). Bull. ent. Res. 73 (1983) 45-52.

178 Wada, Y., Effect of larval density on the development of Aedes aegypti (L.) and the size of adults. Quaest. Ent. 1 (1965) 223-249.

179 Wallis, R. C., and Lang, C., Egg formation and oviposition in bloodfed Aedes aegypti (L.). Mosq. News 16 (1956) 283-286.

180 Washino, R. K., The physiological ecology of gonotrophic dissociation and related phenomena in mosquitoes. J. med. Ent. 13 (1977) $381-388$.

181 Watson, R. D., Williams, T. K., and Bollenbacher, W. E., Regulation of ecdysone biosynthesis in the tobacco hornworm, Manduca sexta: Titre of the haemolymph stimulatory factor during the last larval instar. J. exp. Biol. 128 (1987) 159-173.

182 Williams, R. W., Hagan, N. K. B., Berger, A., and Despommier, D. D., An improved assay technique for matrone, a mosquito pher- omone, and its application in ultrafiltration experiments. J. Insect Physiol. 24 (1978) 127-132.

183 Woke, P. A., Ally, M. S., and Rosenberger, C. R. Jr, The numbers of eggs developed related to the quantities of human blood ingested in Aedes aegypti (L.) (Diptera: Culicidae). Ann. ent. Soc. Am. 49 (1956) $435-441$.

184 Young, A. D. M., and Downe, A. E. R., Male accessory gland substances and the control of sexual receptivity in female Culex tarsalis. Physiol. Ent. 12 (1987) 233-239.

185 Young, A. D. M., and Downe, A. E. R., The action of male accessory gland fluids in the control of sexual receptivity in Culex tarsalis Coq., in: Host Regulated Developmental Mechanisms in Vector Arthropods, pp. 206-211. Eds D. Borovsky and A. Spielman. University of Florida, Vero Beach 1989.

186 Zóltowski, Z., Stejgwillo-Laudanska, B., and Kazmierczuk, J., Physiological and behavioural interpretation of the presence of microtraces of mixed host blood in alimentary tracts of mosquitos of the genus Aëdes Meigen, 1818 (Diptera: Culicidae). Acta parasit. pol. 25 (1978) $351-357$.

$0014-4754 / 90 / 070660-11 \$ 1.50+0.20 / 0$

(C) Birkhäuser Verlag Basel, 1990

\title{
Research Articles
}

\section{The variability of patterns of sexual dimorphism in the hominoid skull}

\author{
P. O'Higgins ${ }^{\mathrm{a}}$, D. R. Johnson ${ }^{\mathrm{a}}$, W. J. Moore ${ }^{\mathrm{a}}$ and R. M. Flinn ${ }^{\mathrm{b}}$ \\ ${ }^{a}$ Morphometrics Laboratory, Department of Anatomy, University of Leeds, Leeds, W. Yorks (UK) and ${ }^{b}$ Centre for \\ Computer Studies, University of Birmingham, Birmingham, Warwks (UK) \\ Received 16 October 1989; accepted 27 February 1990
}

Summary. Univariate and multivariate statistical analyses are applied to a number of cranial dimensions and angles from living hominoids in order to investigate the patterns of sexual dimorphism in these groups. Clear differences in patterns of cranial sexual dimorphisms are demonstrated not only between genera but also within a single species (Homo). These differences overlay the common finding of a sexual size difference in all groups. The results imply that caution is required in using the sexual dimorphisms of living hominoids as models for those anticipated in fossils. Key words. Hominoids; crania; sexual dimorphism; discriminant analysis.

Several recent studies ${ }^{1-5}$ have focused attention on patterns of sexual dimorphism in the primate skull. Sexual dimorphism results from the interaction of natural selection and a number of reproductive, social and other factors ${ }^{6-10}$. Wood ${ }^{2}$, in a study of patterns of cranial and post-cranial sexual dimorphism amongst a range of primate genera concluded that "Apart from a few exceptions variables are consistently sexually dimorphic in all groups, differences between primates being one of degree of dimorphism rather than due to a different pattern of dimorphism". In this context, the term 'pattern' refers to the shape change encountered in going from a female to a male form. It is distinct from 'degree' of dimorphism which implies size rather than shape differences though pattern differences may well be allometrically linked to size differences. It may be possible for the same size difference between sexes in two species to be associated with different shape differences by virtue of the existence of different allometric phenomena in each.

More recently Uytterschaut ${ }^{4}$ and Johnson et al. ${ }^{11}$ have suggested that patterns of cranial size related shape differences and cranial sexual dimorphism ${ }^{4,5}$ show a degree of dissimilarity amongst geographic subgroups of a single species, man. Likewise Oxnard ${ }^{5}$ has shown that differences exist between hominoids in the patterns of sexual dimorphism exhibited by the dentition.

The complex of factors involved in the evolution of sexual dimorphisms might lead us to expect that the pattern of morphological differences between the sexes of a particular primate species should be unique to that species $^{3-5}$ (and ref. cited in Oxnard ${ }^{5}$ ). The extent to which different groups show similarities in their patterns of 